\title{
CULTURA ORGANIZACIONAL E EMPRESAS FAMILIARES DA MARINHA GRANDE - ESTUDO DE CASO
}

\author{
Mafalda Casimiro ${ }^{1}$
}

Resumo: Este artigo baseia-se num estudo de caso cujo objectivo consistiu em caracterizar o perfil cultural de uma empresa familiar da Marinha Grande, considerando aquilo que se manteve inalterável desde a sua fundação e o que mudou, devido a condicionantes internas e externas. Neste sentido, foram tidas em conta mudanças ocorridas na família e na empresa, destacando-se o processo de sucessão em que esta se encontra actualmente, bem como as particularidades do contexto da Marinha Grande. O estudo permitiu-nos concluir que a empresa possui uma cultura sedimentada e coesa, constituída por pressupostos básicos acerca dos seus valores, do seu modo de funcionamento, da sua estrutura e organização e do seu relacionamento interno e externo partilhados pelos fundadores, pela segunda geração da família e pelos funcionários da empresa, de todos os níveis hierárquicos e de todas as áreas funcionais.

Palavras-chave: Cultura organizacional, empresas familiares, sucessão.

Organizational Culture and Family Firms from Marinha Grande - Case Study (Abstract): This paper describes a case study initiated in 2002 which aims at a characterization of the cultural profile of a family company from Marinha Grande, taking into account what has been kept unchanged since its foundation and what has changed, due to internal and external factors. In this sense, we considered changes that have occurred in the family and company, giving special emphasis to the process of succession that is occuring in the present, as well as the specific characteristics of Marinha Grande. The study evidenced a strong and cohesive culture, constituted by basic assumptions - shared by the family and by the employees - about the values of the company, its way of functioning, its structure and organization, as well as its internal and external relations.

Keywords: Organizational culture; family firms; succession.

\footnotetext{
${ }^{1}$ Escola Superior de Educação do Instituto Politécnico de Leiria, Leiria. School of Education - Polytechnic Institute of Leiria - Campus 1 - Rua Dr. João Soares Apartado 4045 - 2411-901 Leiria - Portugal - Tel: (+351) 244829400 - Fax:(+351) 244829499 -E-mail: mafalda@esel.ipleiria.pt
} 


\section{Cultura Organizacional e Empresas Familiares da Marinha Grande - Estudo de Caso}

A cultura de uma empresa, como um conjunto de pressupostos básicos partilhados acerca dos seus valores, do seu modo de funcionamento, da sua estrutura e organização, do seu relacionamento interno e externo, que lhe confere identidade, tornando-a distinta das outras organizações, desenvolve-se através da partilha de experiências e de uma aprendizagem comum particularmente influenciadas por quem lidera a empresa e pelos seus colaboradores mais influentes.

Se considerarmos que a empresa familiar se define pela existência de um elo que estabelece uma importante e permanente união entre uma empresa e uma família, ela pode ser associada a uma empresa cuja cultura é parcial e voluntariamente partilhada, durante um longo período de tempo, com a cultura de uma família (Gallo \& Ribeiro, 1996). Trata-se de uma cultura forte, dado que está profundamente relacionada com a propriedade, o poder e os valores da família, fundamentando a estratégia e a direcção da empresa. A cultura destas empresas tem, portanto, raízes anteriores à própria criação da empresa, radicando no contexto educacional da família. Dentro da família, o fundador da empresa assume um papel particularmente decisivo no perfil cultural desta, determinando, em geral, o desenvolvimento de uma cultura forte e coesa.

Mas a cultura da empresa familiar é uma realidade dinâmica, única forma de a empresa continuar a adaptar-se às novas realidades externas e internas com que, ao longo do tempo, se vai deparando (Martins, 1999).

A nível interno, o perfil cultural é influenciado pelas relações entre as etapas de desenvolvimento da empresa e as fases do ciclo de vida familiar / dinâmica dos relacionamentos familiares. A sucessão, processo pelo qual a direcção de topo passa do responsável máximo pela empresa para o seu sucessor no cargo, constitui indiscutivelmente uma das fases mais marcantes e decisivas no trajecto evolutivo da empresa familiar, implicando que os diversos intervenientes se adaptem aos seus novos papéis e às suas novas posições no conjunto empresa/família (Ussman, 1994). Apesar de perpetuarem muitos dos valores e princípios determinados pelo fundador, geralmente, estes novos elementos introduzem mudanças na empresa que, a médio e longo prazo, contribuem para lhe conferir um perfil cultural diferente.

A compreensão das características culturais de uma empresa não é possível, contudo, sem a análise do contexto exterior da empresa e dos seus membros e a percepção que estes têm dele. Hofstede (1980) é quem mais directa e especificamente revela a influência da cultura nacional sobre a cultura organizacional. Segundo Sainsaulieu (1987, cit. por Gomes, 2000), na organização do trabalho não é possível fazer abstracção da cultura de que 
as pessoas são portadoras. Gomes (2000) enfatiza, contudo, a ideia de que "a organização não é um mero receptáculo de culturas societais, podendo ela própria estar na origem duma cultura, ser um meio portador de cultura ou local de aprendizagem cultural, pelo que faz sentido falar-se de cultura organizacional, a par de culturas societais ou nacionais".

O contexto que enquadra a organização pode, contudo, ser delimitado com diferentes abrangências, o que nos permite falar de um contexto mundial, de um contexto nacional, ou de um contexto mais imediato, respeitante à comunidade local que envolve a organização. No caso das empresas familiares, é particularmente interessante atender às características específicas do contexto local, dado que, em geral, a família proprietária é oriunda do mesmo, podendo nele inserir-se e com ele relacionar-se de forma muito diversa. O prestígio da família na comunidade pode ser anterior à criação da empresa ou estar associado a este facto. Mas, a partir deste evento, a família, como rosto facilmente identificável de uma entidade empregadora, assume um compromisso de longo prazo com a sua comunidade e dele depende a sua reputação. As relações entre as duas são, contudo, dinâmicas. A comunidade não se mantém sempre igual. A família também não. E a empresa familiar tem de se adaptar, ao longo da sua existência, à evolução demogrãfica, económica, industrial, social e cultural do contexto local e às mudanças que ocorrem no seio da família.

O objectivo do estudo que desenvolvemos, no âmbito da dissertação de mestrado sobre cultura organizacional e empresas familiares da Marinha Grande $^{2}$, é a caracterização do perfil cultural de uma empresa familiar da indústria dos moldes deste concelho, considerando aquilo que se manteve inalterável desde a sua fundação e o que mudou, devido a condicionantes internas e externas. Assim, foram tidas em conta mudanças ocorridas na família e na empresa, destacando-se o processo de sucessão em que esta se encontra actualmente.

Foram também consideradas as especificidades geográfica, demográfica, económica, industrial, social e cultural e a evolução histórica do contexto imediato da empresa e da própria família, neste caso, o concelho da Marinha Grande.

\section{Caracteristicas das Empresas Familiares}

É, hoje, inegável que as empresas familiares detêm um peso preponderante na economia da generalidade dos países ocidentais. No caso de Portugal, grande parte das pequenas e médias empresas são familiares,

\footnotetext{
2 CASIMIRO, Mafalda, Cultura Organizacional e Empresas Familiares da Marinha Grande - Estudo de Caso, Dissertação de Mestrado, Escola Superior de Altos Estudos Instituto Superior Miguel Torga, Coimbra, 2003.
} 
tendo muitas delas surgido nas últimas duas décadas e marcado, cada vez mais, a sua presença não só em sectores tradicionais, mas também nalguns domínios mais modernos da indústria e dos serviços, o que afasta a hipótese de a empresa familiar constituir uma figura social e económica em extinção. Além disso, nem todas as empresas familiares são micro e/ou pequenas empresas, podendo constituir grandes organizações, de que ainda hoje são exemplo, no nosso país, o Grupo Espírito Santo, Grupo Amorim, Cafés Delta, entre outras. O estudo de Lima (2003) demonstra esta ideia, revelando o modo como sete grandes empresas portuguesas se relacionam com as grandes famílias que são suas proprietárias.

Mas é um facto que as empresas familiares têm sido apresentadas pelas teorias de gestão convencionais como um primeiro estádio da evolução organizacional, traduzindo-se em formas empresariais pouco evoluídas que, mais cedo ou mais tarde, serão substituídas por outras mais complexas e profissionalizadas. Esta ideia é, contudo, permanentemente desafiada pelo êxito inegável das grandes empresas familiares actuais. O estudo de Denison, Lief e Ward (2004), cujo objectivo consistiu em analisar de forma crítica a cultura e o desempenho das empresas familiares comparativamente com as não familiares, revelou que não só não existem vantagens claras decorrentes da cultura das empresas não familiares, como mostrou que há diversas vantagens associadas à cultura das empresas familiares.

Contudo, este tipo de empresas tem revelado uma grande tendência para a mortalidade precoce, constatando-se que o seu tempo de vida é de cerca de 24 anos (Martins, 1999). De acordo com Gallo e Ribeiro (1996), a esperança de vida média é sensivelmente metade da conseguida nas empresas não familiares.

Embora não exista uma definição consensual de empresa familiar, o conceito preconizado por Gallo e Ribeiro (1996) apreende bem o âmago da especificidade deste tipo de organizações, através da coexistência de três dimensões:

- A proporção da propriedade, especialmente se a mesma for maioritária;

- Envolvimento na gestão da empresa (poder de decisão), sendo relevante que um ou vários proprietários trabalhem na empresa, como gestores ou membros do Conselho de Administração;

- Incorporação da segunda geração, como manifestação de uma intenção por parte da família, de transmissão bem-sucedida da empresa para as gerações vindouras e de continuidade da vivência na empresa de valores próprios da família proprietária. 
Este "carácter especial" das empresas familiares poderá determinar consequências positivas ou negativas (Gersick, Davis, Hampton \& Lansberg, 1997). Neste sentido, se é um facto que elas extraem uma força especial da história, da identidade e da linguagem comuns às famílias, essa intimidade poderá, contudo, comprometer o profissionalismo do comportamento organizacional.

Pode ser mais difícil exercer autoridade com os parentes. Os papéis na família e na empresa podem tornar-se confusos. As pressões da empresa podem sobrecarregar e destruir relacionamentos familiares. Quando trabalhando mal, é possível criarem-se níveis de tensão, raiva, confusão e desespero que podem destruir, de forma surpreendentemente rápida, boas empresas e famílias sadias (Gersick et al., 1997, p. 3).

Trata-se, pois, de uma mistura incontornável da esfera doméstica com a esfera empresarial, o que, segundo Ussman (2004), torna evidente que as mudanças e as decisões mais importantes na empresa familiar tenham a ver com dois sistemas interdependentes: família e organização. Muitos acontecimentos de âmbito meramente familiar - os estudos de um filho, o regime matrimonial da filha, etc. - têm uma importância significativa na empresa, assim como as decisões que colidam com os interesses da família levam a que se tenha em conta a relação família/empresa antes de serem tomadas (Ussman, 2004). No estudo que realizou sobre relações existentes entre famílias empresariais e empresas familiares, Guerreiro (1996, p. 126) constatou que, "para além da maior ou menor presença de familiares na organização formal, uma parte significativa das decisões relevantes para a direcção da empresa é constituída informalmente num espaço relacional familiar externo à organização em sentido estrito", ou seja, num prolongamento informal da direcção empresarial ao espaço doméstico.

Diversos estudos têm concluído que muitos dilemas das empresas familiares, sobretudo a partir da segunda ou terceira geração, estão associados a conflitos entre o controlo do capital e o controlo da gestão (Neves, 2001), sublinhando a necessidade de descrever o sistema da empresa familiar como três subsistemas independentes, mas sobrepostos: direcção, propriedade e família. O "modelo dos três círculos", como ficou conhecido, permite compreender a fonte de conflitos interpessoais, os dilemas de papéis, as prioridades e limites nas empresas familiares, evidenciando que as opiniões das diferentes pessoas sobre as questões relacionadas com a organização só são compreensíveis quando vistas através das lentes dos três círculos.

$\mathrm{Na}$ verdade, segundo Ussman (1994, p. 9), “as pessoas da família encaram a empresa como parte importante da identidade familiar, uma herança e uma fonte de segurança financeira. As pessoas que estão na direcção têm as suas carreiras profissionais ligadas à empresa e defendem que 
esta deve gerar lucros, crescer e assegurar o crescimento dos que nela trabalham, mais do que satisfazer as necessidades da família. Para os proprietários, a empresa é um investimento do qual esperam receber um ganho justo". Assim, a autora considera que o desafio de gerir uma empresa familiar consiste em saber negociar de forma construtiva as relações que se estabelecem entre os subsistemas.

Embora as progressões de desenvolvimento dos três subsistemas propriedade, família e gestão/empresa - se influenciem mutuamente, Gersick et al. (1997) consideram-nas independentes, dado que cada parte muda no seu ritmo próprio e de acordo com a sua sequência. De acordo com Ussman (2004), é necessário, então, introduzir a variável tempo para compreender a problemática das empresas familiares e a particularidade do percurso de vida que cada uma trilha, consoante a forma como gere as relações entre família e empresa, em cada um dos estádios que atravessa. "O tempo traz à família: nascimentos, casamentos, divórcios, estudos, doenças, zangas, abandono, morte, etc. O tempo proporciona à empresa: novas oportunidades de mercado, recessões no sector ou na economia em geral, investimentos, concorrência, novas leis, etc." (Ussman, 2004, p. 57).

Apesar de não existirem duas empresas familiares iguais, é notório um certo padrão de desenvolvimento deste tipo de organizações. Geralmente, são apontadas quatro etapas no seu ciclo de vida.

\section{Criação da empresa}

A empresa surge através da acção impulsionadora e determinada de um indivíduo com características especiais. É de referir, contudo, que podemos estar perante mais do que um fundador, tal como acontece, por exemplo, em empresas fundadas por dois irmãos. As motivações que levam o fundador a criar o negócio podem ser muito diversas.

Por desejos de autonomia e independência, porque percebeu uma necessidade mal satisfeita no mercado, porque desenvolveu um novo conceito de produto ou de fabricação e/ou comercialização ou então por frustrações contínuas no seu local de trabalho, por estar desempregado, por querer fugir da pobreza, por se sentir marginalizado, etc., etc., o fundador dá origem a um pequeno negócio (Ussman, 2004, p. 58).

Em muitos casos, trata-se de pessoas com baixa escolaridade, mas confiantes na sua intuição, na sua capacidade de trabalho e ajuizamento sobre o mercado, empenhando-se de forma determinada na luta pela sobrevivência da empresa, através da criação de um produto ou de um mercado. Dedicado "de corpo e alma" a este "filho" que fez nascer, a sua acção é omnipresente, ocupando-se de tudo, decidindo sobre tudo.

Em geral, os fundadores têm uma orientação técnica e desprezam as actividades administrativas, trabalhando, muitas vezes, na produção, junto 
dos outros funcionários, o que facilita uma comunicação frequente e informal com estes.

Ultrapassada a fase de sobrevivência, a empresa começa, gradualmente, a afirmar-se no mercado e a crescer, lançando novos produtos, conquistando novos mercados, o que obriga a contratar mais pessoal. $\mathrm{O}$ fundador delega responsabilidades a alguns empregados mais experientes e da sua confiança sobre assuntos que, entretanto, se tornaram rotina e afasta-se do trabalho da produção, assumindo cada vez mais a gestão da empresa.

\section{Entrada dos filhos}

A empresa atingiu a maturidade, funcionando de forma mais ou menos rotineira e ultrapassando eventuais crises do sector ou da economia. Os funcionários estão familiarizados com a actividade, mas o fundador continua a controlar todos os aspectos da empresa.

O carácter familiar, que começou a insinuar-se quando os filhos começaram a fazer perguntas sobre o negócio, começaram a vir à empresa, realizando, em muitos casos, algumas tarefas durante as férias escolares, e direccionaram os seus estudos (não raras vezes por pressão dos pais) para cursos relacionados com a actividade da empresa - engenharia, economia, gestão, por exemplo -, afirma-se agora de modo claro.

Entretanto, chegados à idade activa, os filhos começam a trabalhar na empresa, ocupando habitualmente lugares de nível intermédio com a justificação de que possuem formação superior (Ussman, 2004).

\section{Sucessão para a $2 .^{\text {a }}$ geração}

Decorrem alguns anos em que o fundador e a segunda geração trabalham lado a lado, até que se verifica a saída do primeiro, normalmente por doença grave ou morte.

De acordo com Ussman (2004), a transição na direcção é, numa primeira fase, bastante suave, dado que todos os que lidavam com a empresa e na empresa sabiam o que ia acontecer. Geralmente, os filhos do fundador assumem uma forma de comando mais descentralizada que o pai e, no caso de haver mais do que um filho, repartem entre si as decisões. Um dos filhos, nem sempre o mais velho, é reconhecido, contudo, como o líder, ainda que a sua participação no capital seja igual à dos seus irmãos, assumindo, regra geral, uma liderança participativa (Ussman, 2004).

$\mathrm{Na}$ generalidade das empresas, são introduzidas alterações no modo de operar a empresa. A situação de mercado é bem diferente da que se verificava no tempo do fundador, sobretudo na fase inicial, os conhecimentos e competências da equipa de direcção são de outro tipo e, muitas vezes, há mais recursos disponíveis. Em muitas empresas verifica-se um rejuvenes- 
cimento com o lançamento de novas linhas de produtos, com um novo posicionamento no mercado, com novas técnicas produtivas e uma organização mais formalizada, sustentando o seu sucesso até à geração seguinte. Noutras empresas, porém, a segunda geração, por desinteresse, por incapacidade ou por falta de visão, mantém "tudo como dantes", o que se torna insustentável para o negócio, que entra, não raras vezes, em declínio até um estado de marasmo em que sobrevive com muitas dificuldades, culminando, frequentemente, com o fecho da empresa, quando o meio envolvente é muito competitivo.

\section{A terceira geração e seguintes}

Dependendo da situação em que se encontra o negócio e das motivações dos netos do fundador, estes vão entrando na empresa e assumindo, de uma forma mais ou menos empenhada, os destinos desta. Para muitos, a empresa da família já não diz muito do ponto de vista afectivo ou não se enquadra no projecto pessoal e profissional. Para muitos, a empresa da família já não constitui uma herança que são pressionados a aceitar de forma mais ou menos subtil como aconteceu com os seus pais. Assim, neste consórcio de primos, é frequente alguns deles cederem as suas posições no capital a outros, dando-se a primeira e significativa cisão entre parte da família e empresa. Noutros casos, mantêm-se proprietários, mas totalmente afastados da direcção. Há uma tendência para que a autoridade se baseie no capital, mas também na competência demonstrada. Se os membros da família não forem em número e/ou qualidade suficiente para gerir a empresa, pode ser necessário recrutar gestores profissionais que, não dispondo inicialmente de autonomia completa, assumem um papel cada vez mais importante na tomada de decisões.

Perante a necessidade de capital adicional para prosseguir, a gestão familiar opta habitualmente pela abertura ao capital público (obrigações/ acções). Segundo Dyer (1986), nesta fase, a empresa familiar poderá deixar de existir, tornando-se pública, profissionalmente gerida, embora possam subsistir elementos da família na empresa. Mas os casos, poucos é certo, de empresas familiares que se encontram sob a posse e direcção da $4 .^{\mathrm{a}}, 5 .^{\mathrm{a}}$ e $6 .^{\mathrm{a}}$ gerações demonstram que a longevidade deste tipo de organizações é possível se a família souber repensar a empresa e mantiver com ela um laço afectivo.

\section{Cultura Organizacional das Empresas Familiares}

A compreensão do sistema da empresa familiar como três subsistemas independentes, mas sobrepostos - direcção, propriedade e família torna evidente que as características específicas deste tipo de organizações 
influenciam o desenvolvimento da sua cultura. Profundamente relacionada com a propriedade, o poder e os valores da família, trata-se geralmente de uma cultura forte que fundamenta a estratégia e a direcção da empresa. Podemos afirmar que esta cultura tem raízes anteriores à própria criação da empresa, radicando no contexto educacional da família (Casimiro, 2003). Ao contrário das empresas não familiares, o comportamento destas empresas emana não tanto da pressão externa, mas de um sentido de história e moralidade aprendido à mesa de jantar da família (Denison, Lief \& Ward, 2004).

O fundador da empresa assume um papel particularmente decisivo no perfil cultural desta, determinando, em geral, o desenvolvimento de uma cultura forte e coesa. O fundador, mesmo longínquo, poderá ser fonte de informação para a cultura actual da empresa (Rosa, 1994), sendo conveniente perspectivar que a sua origem social, o seu percurso, as suas experiências, o seu meio religioso e ético poderão ser marcantes na fundação. Desempenhando um papel central, quer na família, quer na empresa, a sua influência a nível de valores e de práticas é marcante nestas duas esferas e perdura mesmo depois da sua saída e morte. A forte personalidade, o valor inquestionável de ter criado a empresa, a longa permanência à frente dos destinos desta, o modo centralizador como a dirige e o forte cunho pessoal que imprime na forma de ser da empresa (Ussman, 2004) são aspectos que tipicamente definem o fundador, permitindo-lhe granjear um grande respeito, por vezes, mesmo a veneração, por parte dos funcionários e das gerações seguintes. Não admira, portanto, que, na generalidade dos casos, estas e, sobretudo, os filhos acabem por perpetuar os valores que o pai deles e da empresa determinou.

A cultura da empresa familiar não é, todavia, uma realidade estática, dado que, ao longo do tempo, a empresa se vai confrontando com novas realidades externas e internas, às quais tem de se adaptar. Com a evolução da empresa, os valores iniciais poderão ser progressivamente abalados ou mesmo radicalmente alterados, não só devido às novas realidades do mercado e do contexto externo em geral, que exigem novas respostas e soluções por parte da empresa, mas, também, em virtude da integração de novos elementos familiares e não familiares cujas perspectivas não são necessariamente consonantes com a do fundador.

Neste sentido, têm sido identificados diferentes padrões culturais que são determinados pelos estádios do ciclo de vida das empresas familiares. Em geral, encontramos três padrões culturais básicos distintos: uma cultura dita paternalista, uma cultura mais participativa e uma cultura de cariz profissional.

A cultura paternalista é típica das empresas dirigidas pelo fundador, que se assume como o pater-família, mas também como o pater-empresa, 
providenciando o bem-estar não só da família, como também dos empregados, que considera e trata como a sua família alargada (Ussman, 2004). A responsabilidade social é, aliás, um dos valores fundamentais deste padrão cultural, verificando-se uma preocupação clara com a criação de uma boa reputação na comunidade (Dunn, 1995, cit. por Sorenson, 2000; Rock, 1997), através de um compromisso de longo prazo e de relações de confiança com os seus públicos internos e externos.

A lealdade é outro valor essencial para o fundador. Privilegiando relações directas e informais, cria com alguns dos seus primeiros empregados relações de amizade, dando, contudo, preferência aos familiares para ocupar cargos na hierarquia da empresa. Mas nem a uns nem a outros concede muita autonomia, centralizando em si o poder e esperando lealdade e obediência de todos.

A assumpção de que todos os membros da empresa terão um comportamento baseado em valores comuns e na confiança mútua leva a que a empresa formalize pouco as políticas, regras e códigos de conduta (Dumas \& Blodgett, 1999).

A cultura participativa é característica das empresas familiares na segunda geração, embora também possa subsistir em gerações familiares subsequentes. Ainda muito influenciada pelos valores do tempo do fundador, a principal diferença reside na descentralização do poder, com a consequente delegação de responsabilidades. Os membros da família continuam a ocupar os cargos de topo da hierarquia, mas o crescimento da empresa, a dispersão de capital entre irmãos ou entre primos e uma personalidade diferente leva-os a chamar os seus empregados a uma maior participação na tomada de decisão. Embora os feitos e conquistas do fundador continuem a ser enaltecidos, são introduzidas as primeiras alterações significativas na forma de fazer negócio e no funcionamento interno (Ussman, 2004).

A cultura profissional é um padrão que emerge naturalmente, quando gestores profissionais assumem a direcção da empresa familiar (Dyer, 1986), o que ocorre frequentemente na terceira geração ou seguintes, quando a família começa a ceder participações no capital e o novo ou novos sócios impõem a entrada desses gestores externos. Trata-se de um padrão cultural que já não é típico das empresas familiares.

Alheios à tradição familiar e portadores de modelos profissionais de gestão, estes directivos impõem gradualmente os valores que a família sempre tinha colocado em segundo plano: decisões baseadas em análises racionais e critérios economicistas, procura de eficiência económica e financeira, crescimento da quota de mercado, quotização em bolsa, etc. (Ussman, 2004, p. 84). 


\section{Estudo de Caso}

O objectivo do estudo que desenvolvemos, no âmbito da dissertação de mestrado sobre cultura organizacional e empresas familiares da Marinha Grande $^{3}$, é a caracterização do perfil cultural de uma empresa familiar da indústria dos moldes deste concelho, considerando aquilo que se manteve inalterável desde a sua fundação e o que mudou, devido a condicionantes internas e externas. Assim, foram tidas em conta mudanças ocorridas na família e na empresa, destacando-se o processo de sucessão em que esta se encontra actualmente.

Foram também consideradas as particularidades do contexto imediato da empresa e da própria família, neste caso, o concelho da Marinha Grande.

Com base na revisão da literatura e nos primeiros contactos exploratórios efectuados na empresa a ser estudada, foi-nos possível elaborar um conjunto de questões orientadoras:

1. Existe um forte sentido de identificação dos indivíduos à empresa, que se traduz numa cultura homogénea que se revela em pressupostos básicos partilhados pelos membros da família e pelos outros membros da empresa, ao longo da história desta.

2. O perfil cultural da empresa é influenciado pelas relações entre as etapas de desenvolvimento da empresa e as fases do ciclo de vida familiar / dinâmica dos relacionamentos familiares.

3. O processo de sucessão na empresa constitui um marco de transição entre a Administração dos fundadores e a Administração da nova geração, após o qual se registam mudanças na percepção que os membros da empresa dela têm, mas se mantêm inalteráveis alguns pressupostos.

4. O perfil cultural da empresa é influenciado pela evolução histórica e especificidades geográfica, demográfica, económica, industrial, social e cultural do contexto exterior imediato da empresa, da família e dos trabalhadores que não pertencem à família.

\section{O Concelho da Marinha Grande e a Indústria de Moldes}

Não é possível neste artigo caracterizar exaustivamente o concelho da Marinha Grande e o seu desenvolvimento industrial. Entendemos, contudo,

\footnotetext{
${ }^{3}$ CASIMIRO, Mafalda, Cultura Organizacional e Empresas Familiares da Marinha Grande - Estudo de Caso, Dissertação de Mestrado, Escola Superior de Altos Estudos Instituto Superior Miguel Torga, Coimbra, 2003.
} 
que o historiador José Amado Mendes sintetiza bem o perfil desta comunidade:

A concentração da indústria vidreira na Marinha Grande - a "Manchester Portuguesa", como Guilherme Stephens gostava de lhe chamar -, numa primeira fase e, por indução, de outras indústrias, nomeadamente a de moldes, numa segunda, reflectiu-se sobre toda a realidade do respectivo meio, destacando os seguintes domínios: demografia e economia; urbanização e infra-estruturas; cultura, em geral, e ensino, em particular; dinâmica social e recursos humanos; associativismo e movimento operário, mentalidade e participação política (Mendes, 1988, p. 364).

De acordo com este autor, encontra-se ligada ao vidro parte considerável das diversas elites - empresariais, técnicas e operárias, intelectuais e artísticas -, bem como da população, em geral. "Provam-no, por exemplo, a literatura e a história, a imprensa periódica e a toponímia, os epitáfios nos cemitérios e a arquitectura funerária, a tradição, em suma, a memória histórica da respectiva comunidade" (Mendes, 1993, p. 75).

Se é um facto que a primeira fase do desenvolvimento da Marinha Grande está indissociavelmente ligada à indústria dos vidros, é inegável que a análise da segunda fase de desenvolvimento (desde a década de 30) tem que contemplar a indústria dos moldes. Concentrando a maioria das empresas de moldes no país, a Marinha Grande tornou-se a "capital dos moldes" além de "capital do vidro".

O sucesso do sector dos moldes - reconhecido como um dos mais dinâmicos na criação de emprego, na Marinha Grande (cf. Lima, 1996) tem sido atribuído às inovações tecnológicas, à atenção dedicada à formação e à competitividade no mercado, quer a nível nacional, quer a nível internacional.

\section{Caracterização da Empresa Estudada}

A empresa estudada foi fundada no final da década de sessenta, na Marinha Grande, por dois irmãos, constituindo uma empresa industrial do sector da metalomecânica ligeira, que se dedica à produção de moldes para injecção de plásticos. A sua actividade tem-se dirigido sobretudo à exportação.

A empresa possuía 49 trabalhadores, sendo constituída por cinco departamentos sob a dependência da Direcção-Geral: Departamento Comercial; Departamento Administrativo e Financeiro; Departamento de Qualidade; Departamento de Produção; e Departamento de Compras, Logística e Transporte.

Esta empresa atingiu uma capacidade técnica e um nível de equipamento que lhe têm permitido competir com as melhores do sector. O inves- 
timento contínuo em tecnologia tem sido, aliás, uma das vertentes mais importantes da estratégia da empresa.

Desde a sua fundação até à actualidade, a empresa passou por diversas fases. Pareceu-nos apropriado sistematizar todo o processo de evolução em quatro períodos principais, tendo em conta não só o seu percurso tecnológico, comercial e económico, mas, sobretudo, a trajectória das relações entre a família e a empresa.

\section{1. ${ }^{\mathrm{a}}$ Fase - Desde a fundação até 1978}

A empresa estava localizada na Marinha Grande, em instalações fabris adaptadas para o efeito, numa propriedade da família. Contava com cerca de 30 trabalhadores e encontrava-se em fase de crescimento comercial e financeiro.

Os dois irmãos fundadores não só desenvolviam a gestão quotidiana da empresa, como executavam tarefas na área da Produção, Comercial e Administrativa. Isto implicava um contacto directo, uma grande proximidade e uma situação de cooperação com os funcionários do nível operacional da empresa.

\section{2. ${ }^{\text {a }}$ Fase - De 1979 a 1989}

Em 1979, a empresa transfere-se para as suas actuais instalações fabris, uma vez que aquelas onde laborava começam a revelar-se insuficientes e inadequadas para acompanhar o crescimento da empresa. Neste mesmo ano, é criada outra empresa da família que se dedica à produção de plásticos. Um dos fundadores afasta-se da gestão quotidiana da empresa estudada, para dirigir a empresa recém-criada.

A aquisição, em 1982, de sistemas computorizados de produção e a sucessiva modernização tecnológica leva a que, progressivamente, o outro fundador se distancie do trabalho na produção, centralizando o seu trabalho na direcção da empresa. Precisamente, de 1982 a 1987, a empresa atravessa o período de maior crescimento, sendo considerada uma das melhores empresas de moldes, em Portugal.

Depois de concluir a sua formação universitária, uma das filhas do fundador que se afastou da gestão quotidiana da empresa começa a trabalhar nesta, sem qualquer poder de decisão. $O$ seu marido também integra a empresa, assegurando a gestão de stocks.

\section{3. ${ }^{\mathrm{a}}$ Fase - De 1990 a 2000}

O crescimento económico e comercial da empresa começa a abrandar. Em 1998, a empresa foi transformada em sociedade anónima. A filha do referido fundador começa a participar na gestão da empresa, sem que, no 
entanto, participe na tomada de decisões mais complexas e estratégicas e a sua irmã começa a trabalhar na área da Contabilidade.

\section{4. ${ }^{\mathrm{a}}$ Fase - De 2001 a $2003^{4}$}

O fundador que gere a empresa estudada vende a sua parte do capital da empresa ao outro irmão fundador, deixando de participar na Administração daquela, assegurada agora por este e dois dos seus filhos. Apesar de fazer parte da Administração da empresa, este irmão fundador começa a retirar-se progressivamente da direcção da empresa.

A empresa atravessa grandes dificuldades financeiras, durante dois anos, com risco de ser declarada falência, iniciando, entretanto, uma fase de recuperação. Houve reduções progressivas do número de funcionários e a empresa passou de um efectivo de cerca de 100 pessoas para 46. Alguns funcionários dispensados foram integrados numa outra empresa da família.

\section{Metodologia de Investigação}

Atendendo a que se trata do estudo sobre a cultura organizacional de uma empresa familiar de pequena dimensão - constituída por 49 funcionários - e uma vez que a investigação teria um prazo de tempo muito reduzido, optou-se por uma abordagem metodológica de carácter intensivo e em profundidade, sendo as dimensões da cultura da empresa observadas e analisadas de modo essencialmente qualitativo. Assim, como técnicas de recolha qualitativa, recorreu-se à observação directa das instalações da empresa, à análise de documentos arquivados na empresa e de artigos publicados em jornais e à entrevista em profundidade 5 , tendo-se realizado entrevistas aos dois fundadores e aos dois filhos de um deles, que pertencem actualmente à Administração da empresa. Através da análise de conteúdo das quatro entrevistas, foi possível compreender a percepção, partilhada ou não, que as duas gerações têm da empresa, nomeadamente sobre a sua fundação e evolução, a sua estrutura e organização, as estratégias e mudanças adoptadas e a adoptar, o seu relacionamento com o interior e o exterior, as relações família-empresa, o processo de sucessão dos fundadores e os principais valores que se praticam na empresa.

\footnotetext{
${ }^{4}$ Data de conclusão do estudo.

5 Segundo Bogdan e Biklen (1999), a observação participante e a entrevista em profundidade constituem a "pedra de toque" da metodologia qualitativa. Também Melville (2000) refere que a entrevista em profundidade tem vindo a tornar-se uma prática de recolha de dados cada vez mais aceite na comunidade científica ocidental.
} 
Considerando-se importante o confronto das perspectivas que a família dirigente e os funcionários apresentam relativamente à empresa, para se proceder à caracterização da cultura organizacional, complementou-se a recolha de dados qualitativos com uma técnica de recolha quantitativa, mediante a aplicação de um questionário aos funcionários da empresa, no sentido de compreender a percepção que dela têm, nomeadamente no que se refere à evolução da empresa desde a sua fundação até à actual gestão da nova geração. Nesse sentido, a generalidade das questões é colocada de modo a que os inquiridos se pronunciem sobre as diferenças e as semelhanças em relação a diversos aspectos, entre a época em que a empresa era gerida pelos fundadores e o actual período, com a nova geração a assumir os destinos da empresa. Por exemplo:

"Na sua opinião, em que medida a empresa dava importância às seguintes características dos seus colaboradores, antes da nova geração assumir a direcção da empresa?", sendo exemplos de itens: a lealdade; competência; capacidade de decisão; respeito pelas chefias; qualidade do trabalho realizado, entre outros, avaliados numa escala que varia de 1 a 4 , desde "Nenhuma Importância" (1) a "Muita Importância" (4).

"Na sua opinião, em que medida a empresa dá, actualmente, importância às seguintes características dos seus colaboradores?" (os mesmos itens da questão anterior).

"Na sua perspectiva, antes da nova geração assumir a sua direcção, esta empresa:", sendo exemplo de itens: exercia controlo rigoroso sobre as pessoas que nela trabalhavam; promovia boas relações formais e informais entre todos os seus membros; premiava a lealdade; analisava continuamente o meio externo, no sentido de tentar antecipar as mudanças que poderiam ocorrer e agiam sobre ele, entre outros, avaliados numa escala de 1 a 4 , desde "Não concordo" a "Concordo totalmente".

"Na sua perspectiva, actualmente, esta empresa" (os mesmos itens da questão anterior).

Atendendo a que a empresa possui 49 funcionários, entendeu-se aplicar o questionário à totalidade do universo dos trabalhadores, a quem foi garantida a confidencialidade das respostas individuais.

$\mathrm{O}$ guião das entrevistas em profundidade e o questionário foram construídos com base nas dimensões da cultura organizacional definidas por Vala, Monteiro, Lima e Caetano (1994): Dimensão de percepção da organização; Dimensão de explicação da dinâmica da organização; Dimensão de avaliação da organização; Dimensão de identidade da organização; Dimensão de orientação do comportamento organizacional.

Embora tenhamos procurado evidenciar as regularidades comuns nas respostas dos sujeitos entrevistados, no sentido de identificar os aspectos que são partilhados por todos e aqueles que são partilhados por cada uma 
das gerações, o tratamento do conteúdo das entrevistas foi feito na linha do que Moscovici (1968, cit. por Vieira, 1998) designou de análise descritiva e não de acordo com uma abordagem sistemática e quantitativa. Numa abordagem interpretativa e com algum cariz etnográfico, procurámos identificar o significado que os sujeitos questionados atribuem a diferentes aspectos da vida da empresa, apresentando, contudo, alguma narrativa na primeira pessoa, ou seja, excertos do discurso dos sujeitos, aquilo que Fernandes (2003) considera como "estilhaços" de discurso carregados de valor informativo sobre o objecto de estudo.

Dado que pretendemos perceber a evolução desses significados ao longo da existência da empresa, considerámos adequado enquadrar os aspectos enunciados pelos sujeitos entrevistados em quatro das dimensões definidas por Vala et al. (1994).

No caso da entrevista em profundidade à família, acrescentámos ainda uma dimensão que diz respeito à relação que cada um dos entrevistados estabelece com a empresa, atendendo àquilo que ela representa em termos pessoais.

Em cada dimensão, procurámos identificar os aspectos que são partilhados por todos e aqueles que são partilhados por cada uma das gerações, designadas por Fundadores e Filhos.

\section{Análise das Entrevistas em Profundidade}

\section{Percepção da Organização}

Todos os elementos da família entrevistados definem o relacionamento com os funcionários como familiar, sobretudo quando os fundadores trabalhavam lado a lado com eles. O relacionamento caracterizava-se pelo respeito dos funcionários pela competência técnica e personalidade dos fundadores e pela postura de companheirismo, humanismo e honestidade que estes adoptavam em relação àqueles. Os fundadores apontam o cariz paternalista da sua liderança.

"Nós sentimos os trabalhadores como sendo da própria família e vivemos um pouco mais os seus problemas. Os trabalhadores têm um certo respeito pelo meu paternalismo" (um dos fundadores).

Os funcionários eram leais, empenhados e dedicados aos objectivos da empresa, considerando-se que não houve uma mudança significativa na sua postura ao longo do tempo.

"No nosso tempo, os indivíduos estavam ali a trabalhar connosco, gostavam e se fosse preciso ficavam mais um bocado." (um dos fundadores) 
"Tenho verificado em vários trabalhos que têm acontecido, em que se tem de fazer serão, fazer horas extraordinárias, trabalhar até à meia-noite, trabalhar aos Sábados e até aos Domingos, que existe trabalho de equipa e este existe quando existe um bom relacionamento" (filho de um dos fundadores).

Apesar de todos reconhecerem que os trabalhadores da Marinha Grande têm uma postura caracteristicamente reivindicativa, a Revolução de 25 de Abril de 1974 não é apontada como um factor relevante de clivagem entre os funcionários e a Administração, atendendo ao posicionamento politico dos fundadores, à qualidade do relacionamento que tinham com os funcionários e ao facto de os sindicatos não terem uma capacidade de mobilização tão forte na indústria dos moldes como no sector vidreiro.

"Eu não senti uma separação. Desde o 25 de Abril para cá, ou antes mesmo, eu vivia por dentro dos trabalhadores, alguns anos como empresário, outros como director e outros como trabalhador só" (um dos fundadores).

A mecanização e informatização do trabalho na produção, o crescimento da empresa e a saída de um dos fundadores da gestão quotidiana da empresa estiveram na base do distanciamento dos fundadores do trabalho junto dos funcionários.

Os filhos perspectivam que, desde que assumiram a direcção da empresa, o relacionamento com os funcionários se tornou mais profissional, embora mantenha um cariz afectivo. Aliás, a filha de um dos fundadores mantém uma prática do seu pai:

"O meu pai chega à fábrica e cumprimenta toda a gente, todos os dias. E eu sempre fiz isso. É uma educação que já se tem de casa”.

Ambos os filhos consideram que existe uma comunicação fluída entre todos os membros da empresa, mas, atendendo a que a tomada de decisão está centralizada no topo hierárquico da empresa, trata-se de uma comunicação que visa, essencialmente, manter os membros do nível operacional informados sobre o que se passa na empresa e as decisões que são tomadas.

"Acho que os nossos trabalhadores têm de saber do funcionamento da empresa e o que está a acontecer. As pessoas todas têm de estar envolvidas no processo" (filha de um dos fundadores).

Os filhos enfatizam o seu empenho em promover uma maior auscultação das opiniões, sugestões e propostas dos quadros e chefias da empresa.

"Nas reuniões, todas as pessoas têm de estar implicadas e falar e o Administrador é uma espécie de moderador que dá importância a todas as pessoas. E eu preciso dessas pessoas valorizadas aqui dentro" (filho de um dos fundadores). 
A humildade, a dedicação, a lealdade e a honestidade são características que, quer os fundadores, quer os filhos valorizam nos seus colaboradores, além da sua competência técnica, e que tentam, assim, identificar quando admitem um novo funcionário na empresa.

O sistema de remunerações contempla diferenciações no aumento de salários, dentro da mesma função, com base na qualidade do trabalho desenvolvido e na antiguidade, entendida como reveladora de lealdade e dedicação à empresa.

A capacidade de iniciativa e dinamismo na resolução de problemas é apontada como principal critério para a progressão na carreira, além da antiguidade.

Todos consideram que a empresa possui colaboradores com formação técnica adequada, dado que a empresa sempre ministrou formação na área dos moldes aos seus colaboradores, tendo sido esta particularmente necesSária quando não existia na Marinha Grande ensino especializado nesse domínio. Quando os fundadores trabalhavam junto dos funcionários, eles próprios desenvolviam essa formação, actuando "mais como professores do que como patrões" (um dos fundadores).

Os filhos apontam a Marinha Grande como uma área geográfica privilegiada para, actualmente, encontrar pessoas com a formação técnica desejada.

É focada a dificuldade da Administração, ao longo do tempo, para tomar decisões no que se refere à dispensa e/ou substituição de funcionários que não se adequam às necessidades da empresa, tendo em conta a responsabilidade social e o prestígio da família junto da comunidade da Marinha Grande. Um dos fundadores refere, a este propósito:

"Isso eu também não fui capaz de fazer e deixei uma herança pesada para os que lá ficaram".

\section{Avaliação da Organização}

Todos os entrevistados esperam comportamentos de lealdade, humildade, dedicação e honestidade dos funcionários.

"Há qualidades que nós valorizamos. Uma delas é a humildade. É muito importante. E a seriedade. São dois factores fundamentais" (filho de um dos fundadores).

"Eu acho que uma pessoa rebelde e com um carácter muito forte não se conseguiria integrar" (filha de um dos fundadores).

Por seu turno, consideram que o comportamento da Administração se tem pautado pela honestidade e proximidade com os funcionários, clientes e fornecedores. 
Na relação com os clientes, todos os sujeitos não só valorizam a satisfação das necessidades daqueles, mas, também, a afectividade, referindo a tendência para serem desenvolvidas relações de amizade. Um dos fundadores salienta que "alguns clientes são tratados como família".

O desenvolvimento tecnológico e a inovação, bem como a qualidade do produto, são aspectos sublinhados por todos os entrevistados como desejáveis.

\section{Identidade da Organização}

Todos os entrevistados mencionam os aspectos seguintes como características constantes da empresa:

- A empresa é conhecida na Marinha Grande, dado que este concelho é um meio pequeno, o prestígio da família Matos é antigo e muitas empresas de moldes que existem actualmente foram criadas por funcionários que saíram da Molde Matos, onde adquiriram a sua formação neste domínio;

- Aplicação contínua de tecnologias do mais alto nível;

- Imagem de qualidade do produto;

- Relação honesta e familiar com os funcionários, fornecedores e clientes. A filha de um dos fundadores refere que «é característica da empresa a honestidade com que trabalhamos com toda a gente à nossa volta»;

- A empresa é internacionalmente conhecida e desenvolve relações de amizade com alguns clientes espalhados por todo o mundo;

- Cumprimento das suas obrigações para com os seus funcionários, mesmo num contexto de crise financeira da empresa.

Como aspectos que caracterizaram a empresa num determinado período de tempo e que a distinguiam das demais, são apontados os seguintes:

- A empresa foi a que mais pessoas formou no âmbito dos moldes pelo que um dos fundadores a designa de "Escola da Molde Matos" numa altura em que não existiam cursos especializados nesse domínio;

- A empresa foi a melhor empresa de moldes no país, durante 10 anos:

"Eu creio que a Molde Matos, se não for a mais conhecida no país, é com certeza das primeiras cinco a ser conhecidas no país, quer em qualidade, quer em quantidade, quer em idade" (um dos fundadores). 
Os aspectos a seguir mencionados são características consideradas partilhadas com as empresas do mesmo sector, na Marinha Grande:

- Deixou de haver a cooperação entre as empresas de moldes que existia no tempo dos fundadores, sendo focado o facto de muitas empresas também se encontrarem em processo de sucessão ou com a nova geração já na sua direcção:

"Uma coisa que está muito mal nos Moldes: as empresas não têm falado umas com as outras. No tempo do meu pai e do meu tio, há 10,15 anos, as pessoas da idade deles conversavam muito e eram honestos uns com os outros. Parece que a nossa geração não está a saber fazer isso" (filha de um dos fundadores).

- As empresas de moldes na Marinha Grande não são muito afectadas pela acção dos sindicatos, dado que estes têm uma movimentação mais forte no sector vidreiro, por todo um percurso histórico.

\section{Orientação do Comportamento Organizacional}

Face à crise financeira que a empresa atravessa, justificada por todos com o facto de terem sido feitos investimentos em contextos económicos pouco propícios, numa altura em que a economia mundial teve uma descida significativa, é salientada a necessidade e a tentativa de desenvolver uma gestão financeira e comercial mais racional e profissional.

"O industrial de moldes sempre investia tudo na empresa, tudo o que ganhava era para a empresa. O meu pai e o meu tio diziam que a nossa riqueza pessoal é as fábricas. Havia uma gestão mais emocional. Agora é mais racional e profissional. As empresas têm que se profissionalizar" (filha de um dos fundadores).

Um dos fundadores refere a importância de conquistar novos mercados, dado que a dependência face a um mercado particular pode fragilizar a estabilidade financeira da empresa, no caso de este ser confrontado com uma crise. Os filhos enfatizam o esforço de consolidação da área comercial, através da fidelização de clientes.

Ao nível dos Recursos Humanos, os filhos consideram que têm vindo a estabelecer uma relação mais profissional com os funcionários, embora mantenha um cariz afectivo.

Os fundadores acham importante promover a entrada de novos colaboradores, de "sangue novo" na organização, mas mantendo a empresa com uma dimensão pequena.

"Por aquilo que tenho visto em firmas de moldes na Alemanha, na Suécia, na América e no Japão, uma fábrica quando começa a ter mais de 30 trabalhadores começa a ter problemas. É preciso o encarregado, o encarregado do 
encarregado, o director do encarregado e, portanto, começa-se a perder dinheiro e produção. Penso que a Molde Matos pode vir a ter 35 ou 40 trabalhadores e isso não significa andar para trás. Isso significa evoluir" (um dos fundadores).

\section{Relação Pessoal com a Empresa}

Os fundadores revelam um desejo de continuidade da empresa na posse da família. Também os filhos manifestam a expectativa de que os seus filhos prossigam na direcção da empresa.

"Estou a trabalhar para isso. Gostaria que assumissem. Seria uma honra para mim" (filho de um dos fundadores).

O fundador que está em fase de retirada da Administração da empresa, fala na missão de a salvar da crise financeira em que se encontra:

"Eu não vou vender nada. Se eu falir, se eu falhar, falhou a minha vida e o meu trabalho. Mas quando eu morrer, eu quero morrer empresário. Considero a minha imagem limpa e com determinado perfil".

O fracasso nesse desiderato representa o próprio fracasso pessoal. A identidade pessoal está aqui fortemente sustentada pela posse da empresa da família. Este fundador reconhece a tristeza que sentiria no caso de os seus filhos não terem continuado nos destinos da empresa. O outro fundador gostaria que o nome Matos perdurasse na empresa por respeito aos avós e ao pai.

Os filhos encaram o trabalho na empresa como uma missão da família, nunca tendo encarado a possibilidade de trabalharem noutro lado, sendo que, em casa, embora o pai não tenha exercido uma pressão explícita, nunca colocou essa hipótese. Também para o filho de um dos fundadores, salvar a empresa "faz quase parte de uma vingança pessoal, é uma missão por ser da família".

Todos os sujeitos consideram que os problemas da empresa se misturam com o ambiente familiar:

"Os problemas continuam ao almoço e ao jantar. Não sabemos estabelecer a fronteira entre a esfera familiar e a empresa" (filha de um dos fundadores).

É consensual que isso, por vezes, acarreta discussões, mas o espírito de união da família e a relação de confiança que existe entre todos permitem ultrapassar as tensões no relacionamento familiar. 


\section{Conclusões do Questionário}

\section{Percepção da Organização}

Verifica-se que os funcionários consideram que a anterior geração valorizava nos seus colaboradores a eficiência, a competência e a qualidade no trabalho realizado, associadas a uma capacidade de decisão. No entanto, tudo leva a crer que esta estava confinada à esfera de actuação da função de cada um, atendendo a que a maioria dos sujeitos considera que não era incentivada a iniciativa individual na apresentação de propostas e sugestões relativas ao funcionamento da empresa. $\mathrm{Na}$ verdade, a maioria dos sujeitos parece tender para uma certa passividade, uma vez que raramente procura falar com o seu hierárquico directo e/ou com a Administração para discutir problemas que afectam a empresa, optando frequentemente por comentar esses problemas com os colegas de trabalho. No que diz respeito a problemas que os afectam directamente, os sujeitos, na sua maioria, já procuram sempre falar com o seu superior hierárquico directo, no sentido de discutir os problemas e apresentar propostas. Aliás, $75 \%$ dos funcionários inquiridos consideram que uma empresa deve promover uma comunicação aberta e directa entre todos os seus membros, mas enfatizam a importância da comunicação e transmissão de informação através da hierarquia chefe-subordinado, para o sucesso da organização.

$\mathrm{O}$ respeito pelas chefias - sem que isso significasse um controlo rigoroso sobre os funcionários - e a lealdade são aspectos igualmente tidos como muito importantes para a geração dos fundadores.

Estes aspectos, em particular a qualidade no trabalho realizado e o respeito pelas chefias, continuam a ser, na perspectiva dos funcionários, valorizados pela nova geração.

Os aspectos que a maioria dos funcionários mais valoriza são boas condições de trabalho, reconhecimento do valor profissional, remuneração e benefícios adequados, possibilidade de progredir na carreira, comunicação rápida, directa e eficiente com os outros membros da empresa, boas relações com as chefias e colegas, boa organização do trabalho e oportunidades de desenvolvimento e formação. No entanto, nem todos são apontados como habituais na empresa estudada. Destes aspectos, aqueles que, na perspectiva dos funcionários, estão mais frequentemente presentes no seu contexto de trabalho são as boas condições de trabalho, a comunicação rápida, directa $\mathrm{e}$ eficiente com os outros membros da empresa e as boas relações entre as péssoas.

Em contrapartida, o reconhecimento do valor profissional, a remuneração e benefícios adequados, a possibilidade de progredir na carreira, as 
oportunidades de desenvolvimento e formação e a boa organização do trabalho raramente existem, na opinião dos sujeitos inquiridos.

\section{Avaliação da Organização}

Os funcionários consideram que a anterior geração valorizava, nos seus colaboradores, a eficiência, a competência e a qualidade no trabalho realizado, associadas a uma capacidade de decisão. $\mathrm{O}$ respeito pelas chefias e a lealdade são aspectos igualmente tidos como muito importantes para a geração dos fundadores.

Estes aspectos, em particular a qualidade no trabalho realizado e o respeito pelas chefias, continuam a ser, na perspectiva dos funcionários, valorizados pela nova geração.

O desenvolvimento tecnológico e inovação e a satisfação das exigências dos clientes são valores que a anterior geração preconizava. Este último continua a ser referido pela maioria dos sujeitos como um valor que assume muita importância para a nova geração, a par da qualidade do produto. No entanto, o desenvolvimento tecnológico e inovação são apontados pela maior parte dos sujeitos como sendo um valor com pouca importância na actualidade.

Também a contribuição para o bem-estar e progresso da comunidade envolvente não é um valor percebido pelos funcionários como tendo tanta relevância para a nova geração como tinha para a anterior geração.

\section{Identidade da Organização}

A maioria dos funcionários considera que têm existido na empresa boas condições de trabalho, comunicação rápida, directa e eficiente e boas relações entre as pessoas. A generalidade dos sujeitos revela um sentimento de pertença à empresa, como grupo, e assume que isso tem muita importância para si. Na sua perspectiva, também a empresa reconhece que eles são importantes para ela.

A preocupação com a satisfação dos clientes e com a qualidade do produto vendido tem sido, igualmente, uma constante na empresa, na perspectiva da maior parte dos funcionários.

\section{Orientação do Comportamento Organizacional}

No que concerne às estratégias da empresa para atingir os seus objectivos, os funcionários manifestam, mais uma vez, uma perspectiva passiva, apontando, na sua maioria, a necessidade de uma empresa se concentrar no seu funcionamento interno e reagir às mudanças do meio externo quando elas se fazem sentir. Na verdade, a maioria considera que uma comunicação rápida, directa e eficiente com os outros membros da empresa, a valorização 
e reconhecimento da lealdade e obediência e uma boa organização e coordenação do trabalho, através de procedimentos e normas bem definidos, são necessários para o sucesso de uma empresa. Contudo, os valores que os funcionários apontam como sendo considerados muito importantes pelas duas gerações relacionam-se com a resposta da empresa às exigências do meio externo, embora o desenvolvimento tecnológico e inovação sejam apontados pela maior parte dos sujeitos como sendo um valor com pouca importância na actualidade, o que poderá ter a ver com o abrandamento, nos últimos tempos, dos investimentos em tecnologia, face a um cenário de crise financeira na empresa e ao esforço de desenvolver uma gestão financeira mais racional.

\section{Características Culturais da Empresa}

O confronto das respostas dadas pela família dirigente, nas entrevistas em profundidade, e pelos funcionários, nos questionários, permitiu identificar pressupostos que são partilhados por todos.

Nas entrevistas em profundidade, a família dirigente revelou forte identificação e sentimento de pertença à empresa. Na verdade, os fundadores manifestaram o desejo de continuidade da empresa na posse da família. Também os filhos reconheceram a expectativa de que os seus filhos prossigam na direcção da empresa. Todos os entrevistados consideram que os problemas da empresa se misturam com o ambiente familiar. Também a generalidade dos funcionários revela um sentimento de pertença à empresa como grupo.

A humildade, a dedicação, a lealdade e a honestidade são características que, quer os fundadores, quer os filhos valorizam nos seus colaboradores, além da sua competência técnica. Esta perspectiva é partilhada pelos funcionários. Estes consideram que a anterior geração valorizava, nos seus colaboradores, a eficiência, a competência e a qualidade no trabalho realizado, assim como o respeito pelas chefias e a lealdade. Estes aspectos, em particular a qualidade no trabalho realizado e o respeito pelas chefias, continuam a ser, na perspectiva dos funcionários, valorizados pela nova geração.

A nova geração considera que existe uma comunicação fluída entre todos os membros da empresa, mas, dado que a tomada de decisão está centralizada no topo hierárquico da empresa, trata-se de uma comunicação que visa essencialmente manter os membros do nível operacional informados sobre o que se passa na empresa e as decisões que são tomadas, empenhando-se em promover uma maior auscultação das opiniões e propostas, ao nível dos quadros e chefias da empresa. Embora valorizem a existência de uma comunicação aberta entre todos os membros da empresa, também os funcionários privilegiam a comunicação e transmissão de informação atra- 
vés da hierarquia chefe-subordinado, manifestando a crença de que é importante para o sucesso de uma empresa a coordenação do trabalho através de procedimentos e normas bem definidos. Prevalece, portanto, uma concepção do modelo mecânico-burocrático da organização, assente numa estrutura rígida, na centralização das decisões, na definição rigorosa de funções, procedimentos e normas e num processo de comunicação essencialmente de tipo descendente.

Todos os membros da família entrevistados apontam a existência, ao longo do tempo, de uma relação honesta e familiar com os funcionários, ideia partilhada pelos funcionários que, na sua maioria, consideram que existem boas relações com as chefias e colegas.

Apesar de todos os membros da família reconhecerem que os trabalhadores da Marinha Grande têm uma postura caracteristicamente reivindicativa, a Revolução de 25 de Abril de 1974 não é apontada como um factor relevante de clivagem entre os funcionários e a Administração, atendendo ao posicionamento político dos fundadores, à qualidade do relacionamento que tinham com os funcionários e ao facto de os sindicatos não terem uma capacidade de mobilização tão forte na indústria dos moldes como no sector vidreiro. As respostas dos funcionários também não revelam uma deterioração significativa das relações com a família dirigente.

No que diz respeito às relações da empresa com o exterior, a satisfação das exigências dos clientes, o desenvolvimento tecnológico e a inovação, bem como a qualidade do produto são valores preconizados pelas duas gerações da família. Também os funcionários reconhecem que a satisfação das exigências dos clientes tem sido um valor dominante ao longo da história da empresa. Mas, na sua perspectiva, o desenvolvimento tecnológico e a inovação é um aspecto que não assume tanta importância para a nova geração, ao contrário da qualidade do produto, que é apontada como um dos valores mais relevantes na actualidade.

Em relação à comunidade envolvente, mais concretamente a Marinha Grande, é referida pela família a preocupação de cumprir com a sua responsabilidade social para com aquela, o que se traduz na dificuldade sentida pela Administração, ao longo do tempo, para tomar decisões no que se refere à dispensa e/ou substituição de funcionários que não se adequam às necessidades da empresa. A tentativa de preservar a imagem da empresa junto da comunidade implica a preservação da imagem da família proprietária. Os funcionários consideram que a contribuição para o bem-estar e progresso da comunidade envolvente tinha alguma importância para a primeira geração.

Poderemos concluir que, de acordo com os padrões culturais das empresas familiares que definimos anteriormente, a empresa estudada desenvolveu, de início, uma cultura de cariz essencialmente paternalista, cujas ca- 
racterísticas se mantêm, em grande parte, até à actualidade, subsistindo mesmo à mudança de geração. Inicialmente, os fundadores tomavam todas as decisões sobre as operações da empresa e supervisionavam de perto os empregados, dando-lhes pouca liberdade no desempenho das suas funções. No entanto, parece não haver um controlo rígido e rigoroso sobre as pessoas. Actualmente, essa supervisão é efectuada por chefias intermédias, mantendo-se, por parte da nova geração, a valorização do respeito da autoridade das chefias. Parece, contudo, haver uma maior tendência da nova geração para incentivar a iniciativa individual na apresentação de propostas e sugestões relativas ao funcionamento da empresa, sobretudo ao nível dos quadros e chefias intermédias.

Embora a empresa esteja orientada para o passado, continuando o legado do fundador e da família e assentando o mosaico cultural nas tradições da família, denota-se a ruptura com alguns procedimentos da anterior geração e uma definição de estratégias de acordo com as necessidades percebidas no presente.

\section{Conclusão}

O estudo permitiu-nos concluir que a empresa possui uma cultura sedimentada e coesa, constituída por pressupostos básicos acerca dos seus valores, do seu modo de funcionamento, da sua estrutura e organização e do seu relacionamento interno e externo partilhados pelos fundadores, pela segunda geração da família e pelos funcionários da empresa, de todos os níveis hierárquicos e de todas as áreas funcionais. Verifica-se que, quer a família, quer os funcionários revelam forte identificação e sentimento de pertença à empresa. Estes resultados permitem confirmar a primeira hipótese colocada.

Mas, como já referimos anteriormente, a cultura da empresa familiar é uma realidade evolutiva e não estática. Em termos internos, verificámos que a empresa estudada passou por diversas fases, desde a sua fundação até à actualidade, estando essa evolução entrelaçada com a evolução do ciclo de vida da família proprietária e com a dinâmica dos relacionamentos familiares. A empresa foi fundada por dois irmãos, havendo simetria de posições, quanto ao capital, à direcção e à execução operacional. Quando os filhos de ambos começam a trabalhar na empresa, é notória alguma divergência na forma como os dois fundadores encaram a gestão da empresa e a continuidade desta na família. A decisão de um dos fundadores em vender a sua parte do capital da empresa ao irmão leva a uma concentração da propriedade e do poder numa das partes da fratria. Embora faça parte da Administração da empresa, juntamente com dois dos seus filhos, o fundador proprietário está 
a retirar-se progressivamente da direcção daquela. Este processo de sucessão constitui, indiscutivelmente, a fase mais marcante e decisiva no trajecto evolutivo da empresa, ditando a transição entre a Administração dos fundadores e a Administração da nova geração. Não obstante alguns pressupostos permanecerem inalteravelmente partilhados por todos, o estudo revela que se registam mudanças na percepção que os membros da família e os membros não familiares têm das características da empresa. Consideramos, assim, que a segunda e a terceira hipótese que formulámos estão confirmadas.

Concluímos ainda que a compreensão do perfil cultural de uma empresa não é possível sem a análise do contexto exterior da empresa e dos seus membros e a percepção que estes têm dele. Esse contexto pode ser delimitado com diferentes abrangências, o que nos permite falar de um contexto mundial, de um contexto nacional ou de um contexto mais imediato respeitante à comunidade local que envolve a organização. Embora não devamos negligenciar a alusão que os sujeitos entrevistados fazem a características e eventos de âmbito mundial, como seja a crise da economia, e de âmbito nacional, como, por exemplo, a Revolução de 25 de Abril de 1974, a nossa atenção centrou-se mais na evolução histórica e especificidades geográfica, demográfica, económica, industrial, social e cultural do contexto local, ou seja, o concelho da Marinha Grande. Essas características contextuais permitem identificar traços culturais partilhados pela empresa estudada e por outras empresas do concelho, em particular do sector dos moldes, permitindo-nos confirmar a última hipótese que colocámos. Por exemplo, a nova geração da empresa menciona a cooperação que existia entre as empresas de moldes da Marinha Grande, na geração dos fundadores, e que, na sua perspectiva, não existe na actualidade.

O estudo revelou, contudo, que mais do que uma influência unidireccional deste contexto sobre a empresa, esta tem marcado a evolução e as características desse mesmo contexto. Assim, por exemplo, é apontada uma certa facilidade em encontrar pessoal qualificado na área dos moldes, atendendo ao desenvolvimento na Marinha Grande de um ensino especializado. Mas também é um facto que esta empresa foi uma das que mais pessoal formou nesse domínio, estando ela própria na base da criação de muitas empresas de moldes por parte de ex-funcionários. A distinção estrita entre contexto interno e contexto externo da empresa poderá, portanto, tornar-se falaciosa. A empresa estudada e a sua família são parte integrante desse meio exterior. As entrevistas aos membros familiares revelaram, aliás, que estes não dissociam o prestígio da empresa do prestígio da família na Marinha Grande, o qual remonta a muito tempo antes da criação da empresa. 


\section{Referências}

Bogdan, R., \& Biklen, S. (1999). Investigação qualitativa em educação: uma introdução à teoria e aos métodos. Porto: Porto Editora.

Casimiro, M. (2003). Cultura organizacional e empresas familiares da Marinha Grande: estudo de caso. Dissertação de Mestrado. Coimbra: Escola Superior de Altos Estudos - Instituto Superior Miguel Torga.

Denison, D., Lief, C., \& Ward, J. L. (2004). Culture in family-owned entreprises: recognizing and leveraging unique strengths. Family Business Review, 17, 61-70 .

Dyer, W. G. (1986). Cultural change in family firms: anticipating and managing business and family transitions. San Francisco: Jossey-Bass.

Dumas, C., \& Blodgett, M. (1999). Articulating values in inform decision making: lessons from family firms around the world. International Journal of Value-Based Management, 12, 209-221.

Fernandes, L. (2003). Um diário de campo nos territórios psicotrópicos: as facetas da escrita etnográfica. In T. H. Caria (Ed.), Experiência etnográfica em ciências sociais. Porto: Edições Afrontamento.

Gallo, M. A. \& Ribeiro, V. S. (1996). A Gestão das empresas familiares. Lisboa: Cadernos Iberconsult.

Gersick, K. E., Davis, J. A., Hampton, M. M., \& Lansberg, I. (1997). De Geração para geração. Ciclos de vida das empresas familiares (3. ${ }^{a}$ ed., Trad. de Nivaldo Montingelli Jr.). São Paulo: Negócio Editora.

Gomes, A. D. (2000). Cultura organizacional: comunicação e identidade. Coimbra: Quarteto Editora.

Guerreiro, M. D. (1996). Famílias na actividade empresarial: PME em Portugal. Oeiras: Celta Editora.

Hofstede, G. (1980). Culture's consequences: internacional differences in work related values. Beverly Hills: Sage.

Lima, M. A. P. (2003). Grandes famílias, grandes empresas: ensaio antropológico sobre uma elite de Lisboa. Lisboa: Publicações Dom Quixote.

Martins, J. C. (1999). Empresas familiares. Lisboa: GEPE - Gabinete de Estudos e Prospectiva Económica do Ministério da Economia.

Mendes, J. M. A. (1988). A concentração da indústria vidreira na Marinha Grande. Repercussões socioeconómicas. Comunicação apresentada ao III Encontro de Historiadores Portugueses e Soviéticos, em Leninegrado.

Melville, B. (2000). In-depth interviewing as sociocultural practice. Learning Together, Working Together: Building Communities for the $21^{\text {st }}$ Century, 2, 9-17 .

Mendes, J. M. A. (1993). História da Marinha Grande: introdução e perspectivas. Marinha Grande: Câmara Municipal da Marinha Grande.

Neves, J. C. (2001). A Sucessão na empresa familiar: a estrutura de governo e o controlo do capital. Conferência de Finanças. Universidade dos Açores. 
Rock, S. (1997). Gerir empresas familiares (Trad. de Jaime de Oliveira Leandro). Mem Martins: Edições CETOP.

Rosa, L. (1994). Cultura empresarial: motivação e liderança. Lisboa: Editorial Presença.

Sorenson, R. L. (2000). The contribution of leadership style and practices to family and business success. Family Business Review, 13, 183-200.

Ussman, A. M. (1994). Transferência de geração na direcção das empresas familiares em Portugal. Tese de Doutoramento. Covilhã: Universidade da Beira Interior.

Ussman, A. M. (2004). Empresas familiares. Lisboa: Edições Sílabo.

Vala, J., Monteiro, M. B., Lima, L. \& Caetano, A. (1994). Psicologia social das organizações: Estudos em empresas portuguesas. Oeiras: Celta Editora.

Vieira, R. (1998). Etnografia e histórias de vida na compreensão do pensamento dos professores. In A. Esteves \& J. Azevedo (Eds.), Metodologias qualitativas para ciências sociais. Porto: Instituto de Sociologia. 